\title{
Critical thinking and non-formal Islamic education: Perspectives from young Muslims in the Netherlands
}

\author{
Hülya Kosar Altinyelken ${ }^{1}$ (D)
}

Accepted: 5 July 2021 / Published online: 13 July 2021

(C) The Author(s) 2021

\begin{abstract}
Critical thinking is a highly valued skill in the twenty-first century, and its incorporation into formal school curricula as a core skill is nearly ubiquitous globally. It is considered imperative for educational quality, employability, competitiveness, and for promoting democratisation and social integration. While schools are tasked to promote critical thinking, non-formal Islamic education (NFIE) provided by mosques or by private organisations or tutors is often criticized for its emphasis on rote learning and memorisation, and for fostering an uncritical acceptance of authority. Based on interviews with 27 young adult alumni from four different Muslim communities in the Netherlands, this study seeks to explore the pedagogy of NFIE, with a focus on critical thinking. The accounts of young adults revealed that an emphasis on stimulating critical thinking was largely absent, and there were limited opportunities for interactions, questions, debating or challenging the authority of religious educators or Islamic texts. The traditional pedagogical approach, discouraging attitudes of educators and peers, lack of language proficiency, the young age of learners, and a perceived lack of need for critical deliberations were identified as key challenges. Young adults called for reforming the pedagogy of NFIE to allow for more reflexive, inquisitive and dialogical learning. Some argued that lack of critical deliberation would lead to weakness in the belief structures and faith of new generation Muslims in Europe, resulting in a sense of confusion and disorientation, and limited embodiment of Islamic principles.
\end{abstract}

Keywords Muslims in Europe · Non-formal Islamic education · Qur'an schools · Pedagogy $\cdot$ Critical thinking $\cdot$ Muslim youth

Hülya Kosar Altinyelken

h.k.altinyelken@uva.nl

1 The Research Institute of Child Development and Education, University of Amsterdam, Nieuwe Achtergracht 127, 1018 WS Amsterdam, The Netherlands 


\section{Introduction}

Critical thinking is viewed as one of the most essential life skills that should be promoted in all learning environments, formal and non-formal (LMTF 2013). An analysis of curricular reforms over the past decades reveals that critical thinking has been incorporated as a core skill in formal school curricula in many countries (Altinyelken, 2015). A range of reasons underpin such an emphasis on critical thinking. First, critical thinking is considered beneficial for teaching and learning processes, improving overall educational quality, and stimulating learners to become independent and self-directed learners. One of the underlying premises of child-centred pedagogy or active learning is that improved classroom interactions, student activity, dialogue, and an inquisitive and open classroom atmosphere will positively influence student motivation, interest, and academic achievement (Schweisfurth, 2013). The second reason relates to outcomes extending beyond educational systems, such as increasing economic growth and competitiveness, meeting labour market demands, and actively participating in plural and democratic societies (Hanushek \& Wößmann, 2008; Ten Dam \& Volman, 2004). Moreover, the significance of critical thinking for greater awareness, consciousness raising, emancipation and promoting social justice has been emphasized for several decades by critical pedagogy (Freire, 2009; Giroux, 1988).

Europe's increasing ethnic diversity and the challenges of integrating immigrant communities have sparked a renewed interest in citizenship education, and in critical thinking in particular. In the Netherlands, citizenship education was introduced in 2006, obliging primary and secondary schools to promote democratic values, active citizenship, and social integration (Veugelers, 2007). Within this context, the willingness and ability to critically appraise different viewpoints and to reflect upon justice, equality and democratic engagement are emphasized (Grundel \& Maliepaard, 2012; Westheimer, 2008). However, with its emphasis on rote learning and memorisation, non-formal Islamic education (NFIE; primarily focusing on mosque education) has often been criticised for having poor pedagogical quality and for failing to support children's understanding of the meaning behind the verses, or the underlying rationale of Islamic teachings in general (Che Noh et al., 2014; Cherti \& Bradley, 2011). Furthermore, previous research has implied that some of the values and norms promoted by mosques might be incompatible in some respects with the citizenship competences promoted by mainstream schools (Cherti \& Bradley, 2011). While citizenship education aims to develop competences such as independence, critical thinking, self-reflection, and openness to opposing views (Schuitema et al., 2008; ten Dam \& Volman, 2004), mosques are critiqued for promoting an uncritical acceptance of authority, indoctrinating learners with a one-sided approach, and inhibiting learners' autonomy (Hand, 2002; Perry, 2004).

This study aims to explore to what extent critical thinking is emphasized and stimulated in NFIE in the Netherlands, and what the challenges are to incorporating critical thinking skills in the teaching and learning processes in NFIE, based on the perspectives of young Muslims. It is important to note that NFIE, or 
'Islamic supplementary education', incorporates a range of pedagogical settings, including weekday classes at institutions established by Muslim communities, Qur' an schools organised by mosques on the weekends, and private home tutoring (Akhtar, 2018; Berglund \& Gent, 2019; Selim, 2018; Sözeri, 2021). Despite the public debate and academic discussions regarding its content, theory and philosophy, there has been little empirical research on the pedagogy of NFIE, particularly in the Netherlands (Alkouatli \& Vadeboncoeur, 2018; Hardaker \& Sabki, 2015; Sieckelinck et al., 2012). Moreover, although some studies have referred to critical thinking (Altinyelken \& Sözeri, 2019; Pels, 2014), they did not offer a comprehensive analysis of the challenges to promoting critical thinking skills in NFIE. Furthermore, the majority of studies on the subject focused on a single ethnic or national group (mostly on Turkish or Moroccan communities) (see for example Pels, 2014; Sözeri, 2021), while this study incorporates perspectives from four different Muslim communities in the Netherlands, namely Turkish, Moroccan, Egyptian and Pakistani communities.

\section{Theoretical underpinnings}

Despite the seemingly common assertion that educational and training programs must promote critical thinking (Jawoniyi, 2015), there is no agreement on the definition of critical thinking. As a concept, its use stretches across several fields of study, in particular, philosophy, psychology and the educational sciences. One of the most popular definitions of critical thinking refers to 'reasonable reflexive thinking that is focused on deciding what to believe or do' (Ennis, 1991:1). Critical thinking encompasses 'the component skills of analysing arguments, making inferences using inductive or deductive reasoning, judging, or evaluating, and making decisions or solving problems' (Lai, 2011:2). It requires both dispositions, which can be simply viewed as attitudes or habits of mind, and cognitive skills. Desirable dispositions of an ideal critical thinker involve open- and fair-mindedness, inquisitiveness, reflective scepticism, flexibility, a propensity to seek reason, a desire to be well-informed, understanding of diverse viewpoints, and a respect for and willingness to suspend judgement and entertain diverse viewpoints (Lai, 2011). Cognitive skills, on the other hand, involve questioning and reasoning skills, reflexive thinking, analysis and interpretation of information, seeing both sides of an issue, being open to new evidence that disconfirms one's ideas, reasoning dispassionately, demanding that claims be backed by evidence, asking and answering questions for clarification, interpreting and explaining, and inferring conclusions from available facts (Lai, 2011; Willingham, 2008). It should be also noted that critical thinking does not mean being negative or judgemental in the typical sense of the word, but refers to thinking accurately, clearly, sufficiently, and reasonably (Nosich, 2009).

Some have argued that there is an increasing need for critical thinking skills within religious education, because 'More than ever before, we live in a socially, culturally, religiously, politically, and ideologically complex and pluralistic world that is further characterized by scientific and technological advancements' (Jawoniyi, 2015:47). TV, internet, and other information outlets constantly offer information 
(both factual and fallacious) and images that are connected to religions and spiritual beliefs, and these affect young people's views about religion and the world (Bouma, 2017). Today, access to information from multiple sources is also easier than ever before (Lipiäinen et al., 2020). Through social media, young people are directly exposed to religious information in different forms and with rather diverse and even contradictory messages. Young people can be confronted with multiple religious or non-religious claims and counterclaims concerning certain existential questions and contemporary moral dilemmas. These developments have as a consequence that distinguishing the credibility of various sources of information, and critically evaluating and analysing this massive amount of information are ever more imperative (Jones \& Haydon, 2012). Moreover, young people live in increasingly multi-cultural and multi-religious societies, and in the European context, in an increasingly secular and non-religious context. Supporting young people in dealing with these complexities successfully requires that critical thinking, evaluation and reflection skills be provided in religious education (Jackson, 2014; Jawoniyi, 2015), in both its formal or non-formal modes. In this regard, Hella and Wright (2009:59) also underscored the importance that students engage critically 'with key religious issues and thereby develop appropriate levels of religious literacy and so learn to discern and evaluate different religious traditions and accounts of religion'.

Critical thinking is viewed by some as an inherent part of the Islamic tradition (Ahmed, 2019), such as in classical and ongoing study of hadith (reports of what the Prophet Muhammad said and did; Berglund \& Gent, 2019). However, with regard to current Islamic religious education, there are some concerns that it has failed to catch up with or address the ever-changing religious and pedagogical needs of young Muslims living in diverse Western societies. According to Ucan and Wright (2019:202), current Islamic religious education is 'not comprehensive enough in engaging with diversity within and outside the Muslim community, and in challenging or addressing young Muslims' deep seated conceptions and presuppositions about... religion, society and gender'. NFIE education often adopts a confessional rote learning approach, with a heightened emphasis on the ontological truth claims of Qur'an and Surahs. Such approaches diminish the role of the learner in understanding, interpreting, and making sense of religious phenomena. Moreover, an overemphasis on delivering facts and information about Islam and not introducing learners to diverse perspectives does not appear to stimulate critical thinking, leading to the accumulation of transmitted knowledge that is devoid of learners' own perspectives (Cherribi, 2010; Ucan \& Wright, 2019).

Furthermore, memorisation appears to be a key element of Islamic education. Based on their quantitative analysis involving 179 madrassas in the United Kingdom, Cherti and Bradley (2011) reported that 97\% of madrassas taught Qur'an mostly through memorisation techniques and emphasized reciting things by heart. Likewise, mosques in the Netherlands have adopted what is known as a teachercentred pedagogical approach, based on teachers' transmission of knowledge and learners' passive absorption of the material. Such an approach tends to leave very little space for interactions and undermines the quality and effectiveness of learning processes (Pels, 2014; Soyer, 2020). Furthermore, imams have been criticized for their authoritarian teaching style, harsh discipline, lack of pedagogical knowledge, 
lack of understanding of Dutch culture, and inability to communicate in Dutch (Cherribi, 2010; Witteman, 2009). However, Pels et al. (2006) argued that the new generation of Muslim children, as well as their parents, are increasingly disputing the authoritarian and rigid teaching styles that characterize the religious education in many mosques.

A more recent study (Altinyelken \& Sözeri, 2019:59) at a Turkish mosque revealed similar concerns. One of the mosque teachers commented that even if the majority of second-generation Turks attended mosque education, their learning outcomes were limited due to poor quality mosque pedagogy, and their experiences were mostly alienating. When children asked questions, they got the response: 'Shut up! Allah would turn you into a stone. You cannot possibly ask such a question! Have you become a Kafir [infidel]?'. However, a few teachers in this mosque also indicated that their teaching had become increasingly inquisitive, participatory and open, that they welcomed questions and encouraged children to ask questions: 'There is no shame, no sin in asking questions' (Altinyelken \& Sözeri, 2019:13). Furthermore, in another recent study (Sözeri, Altinyelken \& Volman, 2021) based on classroom observations and interviews with imams and religious educators at Turkish mosques revealed that critical reflexivity was not emphasized 'as there were only a few cases in which the imam and hocas made space for critical questioning by the students'(p. 228), one religious educator even referred to it as a 'problem' that no longer took place in his classes. Therefore, even though student autonomy was promoted through self-study time and individual tasks, challenging the key tenets of Islam or the authority of religious educators tended to be perceived as disrespectful and undesirable.

\section{Methods}

This study adopted a qualitative approach, as it sought to explore and obtain depth of understanding about diverse factors that influenced the space for critical thinking in NFIE settings, rather than focusing on and measuring some pre-determined aspects. A qualitative design is also suitable because the focus was on the perspectives and understandings of the participants, on their subjective experiences and interpretations (Neubauer et al., 2019). Purposeful sampling was used to identify and select information-rich cases for the most effective use of limited resources and time (Patton, 2002). The inclusion criteria were threefold: i. belonging to Turkish, Moroccan, Pakistani or Egyptian Muslim communities, ii. having received some form of NFIE while attending mainstream Dutch schools, and iii. attending higher education at the time of data collection or having graduated from a higher education institution.

In total 27 young adults (18 women and 9 men, aged 18-33 years old) took part in this study (six each from Turkish, Moroccan, and Egyptian communities, and nine from the Pakistani community). Except for four, all participants were born in the Netherlands, and the majority of them lived or studied in Amsterdam. Therefore, the sample consists of a very selective group of highly educated young Muslims as they were regarded especially knowledgeable about and experienced with the topic. These individuals had long years of education and training experience, and they 
were considered to be skilled to communicate their experiences and viewpoints in an open, articulate, expressive, and reflective manner. Indeed, the participants in this study seemed rather open to sharing their opinions and impressions with depth, and insight. This probably also had to do with the fact that all three researchers involved in data collection came from Muslim-majority countries (Turkey, Egypt, and Pakistan), and had experiences with NFIE in their home countries. Hence, they were perceived as both insiders and outsiders (e.g., none of them was born and raised in the Netherlands and they did not have personal experiences of NFIE in this country). These aspects helped to establish good rapport and trust.

The semi-structured, one-to-one interviews were conducted between February 2017 and May 2018 by three different researchers, in English, Dutch, Turkish, Arabic or Urdu, depending on the preference of the participant. Interviews were long, lasting between 1 to $3 \mathrm{~h}$, with a focus on general information about the participants' experience with NFIE, the content of their religious education, pedagogical practices, attitudes of imams or (volunteer) tutors, and openness to asking questions or debating key issues from different perspectives. The interviews were conducted at various settings, mostly on university premises. All interviews were tape-recorded with the permission of the participants and fully transcribed later for analysis. During transcribing, all interviews in Arabic and Urdu were translated into English to allow for analysis and interpretation by the author. The analysis was conducted using Atlas.ti (version 8.043), on the basis of a code list developed from existing literature on the topic. The codes were revised during the process of analysis to incorporate new emerging aspects. To ensure the anonymity of the participants, pseudonyms are used throughout the article, and background information revealing participant identities has been omitted. Any direct reference to mosque names or their locations was also left out.

\section{Organisation of NFIE in the Netherlands}

According to the latest estimates, $6 \%$ of the adult population in the Netherlands is Muslim. The majority of these Muslims have a non-Western background, and approximately two-thirds of them have Turkish or Moroccan origins (Huijnk, 2018). In 2019, the total numbers of persons with a migration background from the four groups included in this study were as follows: Turkey $=409,877$; Morocco $=402,492$; Egypt $=26,152$; and Pakistan $=23,855$ (Statistics Nederland, 2019). However, not all of these immigrants are Muslim; one third of the EgyptianDutch community is believed to be Coptic (Van Meeteren et al., 2013), while 10\% of the Turkish-Dutch community and $5 \%$ of the Moroccan-Dutch community define themselves as non-believers (Huijnk, 2018). The overwhelming majority of firstgeneration migrants came as guest-workers prior to the 1980 s.

NFIE plays an important role across Europe in the intergenerational transmission of Islamic values and norms among new generations (Altinyelken \& Sözeri, 2019). Official statistics do not exist, yet some studies have noted that mosque education is an essential part of Muslim childhood in the Netherlands, reaching up to $75 \%$ enrolment rates among the Turkish-Dutch (Phalet et al., 2012; Sözeri, 
2021). The few earlier studies on the subject revealed that mosque education is 'a transnational endeavour which brings powerful influences from the countries of origin and supports immigrant communities in Europe with the continuity of their religious, cultural and national identities' (Altinyelken \& Sözeri, 2019:61). It is important to note that mosque education is independently organized by mosques and is not subject to the regulatory and supervisory authority of the state institutions in the Netherlands (Pels, 2014). It often occurs on the weekends or after school and is attended by children of primary school age (up to age 12), though some continue until they finish secondary education. The children are mostly taught in same-sex groups, although sometimes the grouping is arranged according to children's age or level of Islamic knowledge. The total number of teaching hours differs per mosque: some mosques only offer 2-3 h on Saturdays, while others schedule 3-h long classes on both Saturdays and Sundays. Although imams assume educational responsibilities and teach some groups, particularly in larger mosques, classes are mostly taught by volunteer 'teachers'. Despite being called teachers, they are not actually trained in pedagogy, and are selected based on their knowledge of Qur'an, language skills in Arabic, and motivation (Akhtar, 2018; Sözeri, Altinyelken \& Volman, 2019; Selim, 2018).

Mosques in the Netherlands are predominantly Sunni, and they tend to be segregated along ethnic/national lines. Since the Egyptian and Pakistani communities are relatively small, in the absence of nearby mosques affiliated with their national groups, their children may attend Moroccan or Surinamese mosques (Akhtar, 2018; Selim, 2018). There is no unified curriculum or teaching program adhered to by all Sunni mosques. Even mosques from the same ethnic/national groups use different educational materials, mostly imported from Turkey, Morocco, or Egypt. The teachings mainly focus on the five pillars of Islam; the life and teachings of the prophet Mohammad; Islamic history, values, and norms; Qur'anic memorisation; and the performance of rituals. In addition to Islamic knowledge, instilling a Turkish and Muslim identity in children appears to be a key objective in Turkish mosques (Altinyelken \& Sözeri, 2019).

\section{Critical thinking in NFIE in the Netherlands}

Young adults who took part in this study received NFIE in three different forms: while the majority were enrolled in educational programs provided by mosques, others received religious education from private organisations established by the members of the Muslim community or from private tutors who gave regular classes to children individually or in groups in home settings. The majority of Turkish- and Moroccan-Dutch young adults attended mosques' religious education programs, while enrolment at independent private organisations was more common among Egyptian-Dutch youth. The majority of Pakistani-Dutch youth, on the other hand, had a private tutor at home, called a Qari, which appears to be a popular practice in Pakistan as well. Parental preferences for a Qari were due to previous unfavourable experiences at mosques or concerns about the content of religious education: 
My parents did not want us to go to mosque. My father has been here for 45 years and he has seen a lot of things. He was just afraid that we would learn things about Islam that are not really Islam. (Arisha, female, Pakistani-Dutch)

Based on their own subjective experiences, the participants were first asked if and to what extent critical thinking was promoted through NFIE. The overwhelming majority of the participants maintained that an emphasis on critical thinking was mostly absent in their religious education experiences. The participants pointed to a lack of attention to critical thinking as a skill in their religious education, but also indicated that the learning environment was often not open for asking critical questions or contemplating the subjects learnt. When some of them attempted to challenge what was being communicated, they felt discouraged by the reactions of peers and teachers. However, a few participants noted that they simply did not feel the need to ask questions or discuss subjects. The main learning objective was memorising Qur'an, which did not elicit the need for questions or dialogue. Moreover, some had parents, sisters, and brothers with whom they could converse about these subjects. Only three participants stated that there was space for questions and discussions, while acknowledging at the same time that there were some unspoken limits to what was debateable:

The beautiful thing about Islam is that it actually encourages you to question the religion. In the Qur'an, it is emphasized so many times that you have to reflect, you have to think, you have to ask questions, so I would say, that even though there are some mosques out there that indoctrinate the youth... most of the mosques and teachers, they have this mix of critical thinking and reflecting, but also that you shouldn't question it too much. (Wali, male, PakistaniDutch)

Two participants experienced such space for reflection when they attended Sohbets (Talks in Turkish) organized for youth in upper secondary education at Turkish mosques. Another participant (Belal, male, Moroccan-Dutch) conveyed that his religious educators underscored the importance of not accepting everything they heard at school or in other spaces, that they must first read further, look at the subject critically and then make a decision for themselves. However, in his experience, the emphasis on critical thinking was particularly directed towards knowledge and messages young Muslims encountered in spaces outside of NFIE settings. Karam, a Moroccan-Dutch young man, confirmed that his religious educators were also keen to emphasize the significance of being critical of what they learnt or heard at secular, mainstream schools. He suggested that the underlying reason for this emphasis was rooted in the perceived clash between Moroccan-Dutch and native Dutch people (e.g., arguments that the broader society viewed Moroccan-Dutch youth as 'criminals'), and that there was 'a lot of false information out there about Islam'.

Some of the participants also discussed the implications of the absence of critical thinking in their religious education. Some suggested that lack of openness or critical reflection would lead to weakness in one's belief and result in vulnerability of one's belief structure. For instance, Firuze (a Turkish-Dutch young woman) shared that her mosque teacher emphasized the importance of knowledge and of being conscious of 
the reasons behind Islamic rules and moral values. Her teacher likened one's belief to a candle: If you do not sustain the candle's light with knowledge, then it can be blown out by the slightest wind. Such dangers were particularly pertinent in a country where the Muslims are a minority and surrounded by an increasingly non-religious society. Shazia and Suraya shared similar sentiments on this issue. They both had a positive image of Western culture and upbringing in terms of its openness to questions and inquisitive attitudes. They underlined that lack of openness to (critical) questions in mosques can lead to unfavourable outcomes, such as teachings failing to convince children and youth about the necessity of following certain Islamic rules and practices, resulting in their limited eventual embodiment by new generation of Muslims:

I feel like the positive things of the Western upbringing is that you are allowed to ask questions and that makes you understand the religion better. Because if you are, like, indoctrinated and it is said to you, this is how it is, don't ask questions, then I don't think that will lead to favourable outcomes. (Shazia, female, Pakistani-Dutch)

You know in Western culture you can ask anything, anything... I think that is the best thing. Because if you are going to tell me, don't go near the water and I will say why, and you will say, because I have said so, that's not good. Why?

Because I will do it. You haven't told me the reason, so how will I know that it's wrong?... I think you should give children the opportunity to ask. (Suraya, female, Pakistani-Dutch)

Qurrat, another Pakistani-Dutch woman, confirmed these concerns, adding that such circumstances lead to a sense of confusion and disorientation among Muslim youth: 'Muslim youth is under threat... They have questions and they are told that they cannot ask these questions.' The majority of the participants denounced blindly following Islam and said that they were in favour of more questioning and critical reflection in NFIE, and more generally within the Muslim community. Shrine (an Egyptian-Dutch young woman) believed that a lot of Muslim youth in the Netherlands wanted to be self-reflective and engage in critical discussions of Islam, but they feared two things: Islamophobic backlash from non-Muslims and the 'judgmental or condemning voice' of the conservative people within the Islamic community. Those who express critical viewpoints were quickly labelled as kafir by conservative groups. According to Shrine, these two dynamics made it very difficult for the Muslim youth to speak out at mosques or beyond: 'A lot of Muslim youth feel reluctant to speak out because they don't want to be seen as a traitor. I think that is really important'. This phenomenon has been also noted in some other studies as impeding intra-community critique, masking gender inequalities and power imbalances (Kalin, 2011) and justifying a sense of self-preservation (Niyozov, 2016).

\section{Challenges to promoting critical thinking in NFIE}

A key objective of the study was to explore the underlying factors and dynamics that limited critical thinking in mosques and in other non-formal learning spaces. From the perspectives of young Muslims, the following challenges were identified in this 
study: the traditional pedagogical approach, the discouraging attitudes of teachers and peers, lack of comprehension of the language of instruction, the young age of most learners, and a perceived lack of need for debate in NFIE.

\section{Traditional pedagogical approach}

The pedagogical approach used by religious educators was highlighted as an important impediment to critical thinking, and this was brought up by the participants more frequently compared to the other aspects. Several young adults noted that their religious education was primarily focused on memorising and reciting Qur'an, and writing and reading in Arabic. There was limited space for interactions between learners or between learners and teachers, or for contemplation, reflection, and discussions. Learning was a matter of teachers explaining certain topics and learners receiving these explanations through listening quietly. For instance, Hager (female Moroccan-Dutch) explained that she used to go to mosque for two or three hours. She and other learners in her class would simply spend this time sitting and listening without making any comments or having interactions. Reda (male, Egyptian-Dutch) also recalled similar experiences: 'It was always explanation, and that we do the reading, that someone reads out loud, and memorising Qur'an, and that is it... it was not necessary that anyone asks anything'.

Deniz was very positive about the subjects he learnt at mosque, and even at a young age he greatly enjoyed the topics he studied. Yet, he was also discouraged by the pedagogical approach he observed among mosque educators:

What you see is... there is no asking of children what do you think, how is this for you? It's like a one-way street where you learn about certain subjects and this is how it is... there's no connection with the youth, you know. You have the teacher and you have to do what the teacher says. He's teaching a class. If you talk during it, it's not ok. It's like with old schools where there is no real interaction or creating an atmosphere, bringing the whole group together.

(Deniz, male, Turkish-Dutch)

Deniz added that the pedagogical practices at mosque reflected imams' or volunteer teachers' own educational and pedagogical experiences during their schooling, suggesting that this was how mosque educators themselves were trained, so 'they did not know any better.'

\section{Attitudes of Teachers and Peers}

A few young adults remarked that they had 'nice teachers': they responded to the questions clearly and encouraged children to pose inquisitive questions for further clarification of the subject matter. Yet, various participants concurred that the attitudes of teachers discouraged them from asking questions. Some did not feel connected to teachers or did not experience a bond with them. Hence, they did not share many of their questions, doubts, or inner dilemmas. Deniz referred to his teachers as 'patriarchal, authoritative kind of people' and noted: 'There 
was no openness and it [the classroom environment] was quite rigid. So, I didn't like the way the teachers were behaving, to be honest'. In some other contexts, a questioning attitude was seen as interference in the teaching process, or 'rude' and 'disrespectful' to the authority of imams or volunteer teachers. Shazia for instance talked about how she was afraid to ask questions. Her fear was informed by her socialisation into Pakistani culture which did not allow or appreciate any challenging attitudes to adults in authority positions.

Some other young adults talked about how they feared their religious education teachers and felt intimidated by them. For instance, Qurrat (female, Pakistani- Dutch) remarked that she had 'a very scary teacher', so she and other learners were 'very scared of him'. Hence, these young adults did not feel comfortable asking questions. In few cases, this involved a fear of corporal punishment as well. Among the participants, two Dutch-Egyptian and one Dutch-Moroccan young adult explicitly mentioned witnessing corporal punishment:

I was hit there [laughing]. I used to be hit when I didn't know something. In the normal school [the mainstream schools], I didn't get hit. So, this made me afraid. Aside from this, I had no problem with studying. But just this hitting thing made me afraid. (Mohammed, male, Egyptian-Dutch)

Despite a seemingly discouraging environment, some of the participants nevertheless attempted to ask questions or challenge what was told. However, they received disheartening reactions from their teachers (or even peers) because they were told they were not allowed to ask questions, or their questions were simply dismissed or not addressed adequately. Qurrat (female Pakistani-Dutch) recalled the occasions she or other learners raised questions: 'They [educators] would say "Well, if it is like this, then it is like this". So, there was not really an answer... they say to children 'You cannot ask this question,' but why can't you ask questions? (Qurrat, female, Pakistani-Dutch). In some other cases, the young adults experienced criticisms (sometimes with a hostile tone) for raising a (critical) question and challenging the authority of the educators or the authenticity of Islamic teachings.

I remember that sometimes I spoke out against [things]. For example, when the teacher said that women should not travel alone, and I remember I spoke out. Then... but not only the teacher became mad at me, even my peers were like 'What are you saying?' It was really discouraging to disagree with whoever was in front of the class... It [asking questions] was wrong because you are doubting an authority, doubting in that sense also the authority or the word of God, I think. I just felt strongly discouraged in general from asking critical questions. (Shrine, female, Egyptian-Dutch)

Asli (female, Turkish-Dutch) was another young adult who was critical of some of the things she was told during her mosque education. However, she felt lonely in the group with her questioning attitude, and felt that it was unsafe for her to raise questions or challenge openly what was being said: 'If you are the only one that does not conform to the dominant view, you do not dare to challenge'. 


\section{Language comprehension}

The primary language educators use to convey Islamic knowledge or religious practices in NFIE tends to be the official language of the country of origin of the migrant community (Akhtar, 2018; Selim, 2018; Sözeri, 2021). All Turkish mosques express a conscious preference for Turkish as the main language of instruction, since teaching Turkish to new generations is a key goal for the mosque communities, and is perceived as critical to the cultural and religious nurturance of the new generations of Turks in the Netherlands (Altinyelken \& Sözeri, 2019). In this study, similar trends were observed in other Muslim communities as well: Moroccan and Egyptian communities using primarily Arabic, and the Pakistani mosques or private tutors using Urdu as the medium of instruction. Teaching and learning in Arabic was important for Moroccan and Egyptian communities not only because it is the official language of their country of origin, but also because Arabic is the language of the Qur'an:

I think it is important for you as a Muslim student to know how to read the Qur'an, to interpret it, at least be able to study it on your own. It was very important [learning Arabic], otherwise, they [parents] would not have sent all my little brothers and sisters as well. (Sabreen, female, Dutch-Moroccan).

At Pakistani mosques, speaking Urdu was viewed as important to foster a connection with learners' roots and strengthen cultural associations. Most of the Qari's had basic language skills in Dutch but they also conducted their classes in Urdu. Language choices were also partly dictated by the fact that the majority of imams are appointed or recruited from the Muslim communities' country of origin (mainly from Turkey and Morocco), and lack proficiency in Dutch. Despite this heightened emphasis on Turkish, Arabic or Urdu, for young adults who were born and raised in the Netherlands, teaching and learning in these three languages were challenging. Arisha, for example, recalled that her Qari would get angry if children spoke in Dutch, and he would remind them that Urdu was the language of instruction. However, as Arisha (female, Pakistani-Dutch) reported, insistence on Urdu limited interactions, 'You really had to think before speaking in Urdu because nobody's [Urdu] was perfect.' Qurrat, another Pakistani-Dutch youth, resonated with these concerns, confirming that Pakistani imams' or other religious educators' lack of mastery of Dutch created a communication barrier between the educators and the learners. Similarly, at mosques from other communities, learners mostly encountered teachers who did not speak Dutch at all, or who spoke only a few words. Hence, there was not a common language in which both teachers and learners could converse fluently. In some mosques, it was more appropriate to speak only in Arabic:

If I talked to him in Egyptian, he would act as if he does not understand, and I did not speak good Arabic to the extent that I could ask him something, and if I would ask something, there was no one who spoke good Dutch. (Reda, male, Egyptian-Dutch) 
Consequently, not being fluent in Arabic, Urdu or Turkish limited learners' comprehension, their interactions, and their capacity and willingness to raise questions and engage in a dialogue with the educators or other learners.

\section{Learners' developmental stage}

Some participants also highlighted that critical thinking develops with age, and usually at the ages when they received Islamic education (mostly between 6 to 12 years old), they were simply too young for reflexive thinking, for having a questioning attitude or for daring to raise a critical question. For instance, Belal (male, Moroccan-Dutch) remarked, 'We were young... what kind of [critical] questions can you have when you were at such a young age?'. Some participants noted that at such a young age, they were more inclined to accept things at face value and accept what they were told without questioning much:

You are very young, you know, it is easier to just take things as they have been taught to you than like, right now. It is different, I am 23 years old. Yeah, you just see things differently, you think differently about the world, and you do not necessarily need someone to motivate you to think critically. (Fatma, female, Moroccan-Dutch)

Critical thinking was viewed as a skill that developed at later stages of life, as children mature and acquire more knowledge throughout their educational trajectories, mostly at the higher education level, due its emphasis on research, empirical knowledge, and discussions.

\section{A perceived lack of need for critical deliberation}

The accounts of these young adults also pointed to a general understanding that religious education does not require much critical deliberation, since the rules were laid down a long time ago. The purpose of religious education is then to communicate to young Muslims what is right and wrong, what they must and must not do, and things they must accept or reject. Additionally, critical deliberation may not be required because there are simply no answers to some of the questions:

I have been taught from a young age that there are not answers for things if you go through religion... When I was very young, it was said that there is no answer for this. You just have to do it. (Qurrat, female, Pakistani-Dutch)

Wali, on the other hand, argued that Islam encourages Muslims to question their religion, that the Qur'an repeatedly emphasizes the importance of reflection, thinking and asking questions. At the same time, he suggested that there should be limits to what can be questioned:

There are certain things, like you should draw a line somewhere. For instance,... Allah has decided, only a man can lead the prayer if men and women pray together. These are things that are just there... There is no proper 
logic behind it. Allah has put these rulings this way and you have to accept it.

(Wali, male, Pakistani-Dutch)

The perceived perfection of Islam as a religion and the Qur'an as a holy book were brought up as another reason why critical reflection was redundant and even undesirable. A consistent message they received was that Qur'an embodies the ultimate knowledge and no one cannot doubt what is conveyed through this sacred book. As Shrine (female, Egyptian-Dutch) explained, Islam was often taught as the most perfect version of Judaism and Christianity, and as superior to other religions because 'it is the final message and the most perfect message of the god that is delivered to humankind'. Moreover, there was a strong sense that further debates and interpretations of the text was not needed, 'because everything is already debated and interpreted'. Shrine further added that since Islam is taught as a perfect religious doctrine, questioning it, doubting some elements, engaging in self-reflection, or attempting to reinterpret Islam were perceived as inappropriate. Such actions were believed to make a Muslim less of a firm believer, assuming that applying critical thinking to one's religious beliefs would weaken one's faith and religious convictions.

\section{Conclusion}

This qualitative study incorporates the perspectives of 27 young Muslims from four communities in the Netherlands in order to explore whether and to what extent critical thinking is promoted in NFIE and what the challenges are. The narratives of young adult alumni suggest that they experienced limited space for critical thinking in their NFIE experiences or encountered little attention to developing critical thinking skills. As such, the findings of the study corroborate observations made in earlier studies in the Netherlands or elsewhere in Europe (Che Noh et al., 2014; Cherribi, 2010; Cherti \& Bradley, 2011; Pels, 2014). This study expands our understanding about the underlying reasons for the absence of critical thinking in NFIE through discussing factors such as an emphasis on rote learning and memorisation, discouraging attitudes of religious education teachers and peers, lack of proficiency in the language of instruction, the young age of learners, and a perceived lack of need for debate.

It is important to highlight that the majority of imams in the Netherlands, but also in other European countries, originate from two Muslim majority countries: Turkey and Morocco. These imams are oftentimes critiqued for having inadequate professional training, for lacking familiarity with the language and culture of the Netherlands, and for failing to connect with the life-worlds of new generations of Muslims born in Europe (Sözeri, Altinyelken \& Volman, 2019; Cherribi, 2010). Moreover, most of the training is carried out by volunteers who have not been trained pedagogically for this role (see also Sözeri \& Altinyelken, 2019). Consequently, even if they wanted to adopt a more critical pedagogy, they probably lacked the knowledge and the skills to stimulate discussions and address critical inquiries on sensitive issues. As Sieckelinck, Essousi and El Madkouri (2012:150) also confirmed, 'There 
is a big need for educational reform in European mosques. Many volunteers or leaders do not possess any professional quality that allows them addressing children's sores and uncertainties'. The same can be said for educators at independent private institutions, as well as private tutors, as the majority of them were not professionally trained in pedagogy either.

While the pedagogy of NFIE has been to a large extent critiqued for inhibiting critical thinking, it should be noted that similar debates have been taking place in mainstream schools around the world as well. The so-called traditional teaching, which is characterised by its expository form and narrative character, has been perceived as obsolete and inadequate for the twenty-first century (Altinyelken, 2011; Chisholm \& Leyendecker, 2008). This is mainly because it tends to relegate education to being an act of depositing, where teachers make deposits and learners receive, memorise, and reproduce them in periodic exams (Freire, 2009). Similar to some other major religions, Islamic education also emphasizes verbatim mastery of sacred texts. Some scholars view memorisation as a distinct form of learning in religious education, arguing that it is crucial to develop 'a child's intellect, moral character, and religious community membership' (Moore, 2012:298), and it 'deepens students' spirituality and offers comfort and security through increasing their awareness of the presence of God' (Boyle, 2006:494). Although memorisation of sacred texts might be important for a range of reasons, and it might remain a central element of religious education for legitimate reasons, as Che Noh et al. (2014) suggested, such emphasis should not be at the expense of ignoring learners' comprehension of the meaning of the verses and other important Islamic knowledge.

In this study, most young Muslims had developed a critical position concerning a pedagogical practice that tended to silence them. Their sense of urgency for incorporating openness, interactions and critical reflection contradicts some religious educators' conviction that there is no need for critical deliberation in Islamic religious education, since Islam is already 'perfect' and there are dangers associated with a critical stance, such as becoming a less firm believer. Some young Muslims in this study argued for an opposite position: that is, lack of critical deliberation would lead to weakness in the belief structures and faith of new generation Muslims in Europe, resulting in a sense of confusion and disorientation. Waghid (2014) confirmed that a minimalist approach to tarbiyyah (nurturing) is oftentimes associated with the uncritical acceptance of facts about Islam. Through such approaches, a learner might become 'an uncritical believer who does not bother to question the merits and demerits of his or her beliefs' (Waghid, 2014:336).

In a recent case study of a Turkish mosque in the Netherlands (Altinyelken \& Sözeri, 2019), parents confirmed the need for more interactive lessons, questions, and discussions. They believed that only through such interactions can new generations be conscious Muslims, and their improved awareness can equip them with the knowledge and skills to respond adequately to inquisitive questions from their non-Muslim peers and teachers. In the same study, some mosque teachers emphasized the urgency to 'transition from a fear-based pedagogy towards a love-based pedagogy which highlights and incorporates God's qualities, such as compassion, graciousness and forgiveness' (p. 13). They believed such a transition was urgently needed in order 'not to lose' the new generation of Muslim children in Europe. The 
narratives of young Muslims in this study also underscored the importance of creating an atmosphere of respect and trust, and a safe space to learn in NFIE programs. This is important to consider as Islamic educational communities in Europe are currently and increasingly recognising the significance of critical thinking and an engaged pedagogy encompassing dialogue and inquiry (Ahmed, 2019; Waghid, 2014). For instance, Ahmed (2019:21) called for a dialogical halaqah (Islamic oral pedagogy) to 'generate more inclusive practice by providing a space that facilitates children and young peoples' collective self-reflection and exploration of their faith.' She believes such a dialogical pedagogy draws on foundational Islamic educational ideas based on a tradition of dialogue and reflexivity, and it can 'complement existing rote-learning and transmission-based pedagogies'.

There are some limitations to this study as well. Due to its small purposeful sampling focusing on highly educated young Muslims, the findings cannot be generalised to all Muslim youth nor to all NFIE in the Netherlands. Future research involving quantitative measures with a focus on aspects identified in this study would be useful to determine the extent to which these findings can be generalised. Furthermore, this study focused on the perspectives of young adults who participated in NFIE in the past. Hence, the analysis is based on their recollections of time spent in NFIE settings. Future studies can explore this subject among primary or secondary school-age children who are receiving NFIE at the time of data collection, and incorporate other qualitative research methods, such as extensive observations. Such an approach can help to avoid overreliance on participants' self-reports and contribute to identification of any possible reform of NFIE over the past decade to allow for more open, exploratory, and inquisitive learning.

Acknowledgements I am most grateful to all young Muslims who took part in this research and shared their critical reflections, and to Nazek Magdy Selim and Yusra Akhtar for their research assistance.

Funding This study was funded by the Talent Programme Veni of the Dutch Research Council [Nederlandse Organisatie voor Wetenschappelijk Onderzoek], grant number 451-16-002. The funder had no role in study design; in the collection, analysis and interpretation of data; in the writing of the report; and in the decision to submit the article for publication.

Data availability The interview data for this research is not publicly available due to the sensitivity of the research. Besides, at the time of data collection, the participants did not grant specific permission to deposit the data in a public repository. On the contrary, the participants particularly emphasized the use of the data exclusively by the researcher(s) who conducted the interviews.

Code availability Not available due to confidentiality and sensitivity of the subject.

\section{Declarations}

Ethical approval Ethical approval for this research was granted by the appropriate authorities at the University of Amsterdam. The approval letter is available upon request.

\section{Conflict of interest None.}

Open Access This article is licensed under a Creative Commons Attribution 4.0 International License, which permits use, sharing, adaptation, distribution and reproduction in any medium or format, as long as you give appropriate credit to the original author(s) and the source, provide a link to the Creative 
Commons licence, and indicate if changes were made. The images or other third party material in this article are included in the article's Creative Commons licence, unless indicated otherwise in a credit line to the material. If material is not included in the article's Creative Commons licence and your intended use is not permitted by statutory regulation or exceeds the permitted use, you will need to obtain permission directly from the copyright holder. To view a copy of this licence, visit http://creativecommons.org/ licenses/by/4.0/.

\section{References}

Ahmed, F. (2019). Educating the dialogical Muslim-self: Revitalising traditional Islamic halaqah for 21st century intercultural education. Research Intelligence, 140, 21-22.

Akhtar, Y. (2018). Between the school and the mosque: Young Pakistani Muslims negotiating citizenship in the Netherlands (Unpublished MA thesis). Amsterdam: University of Amsterdam.

Alkouatli, C., \& Vadeboncoeur, J. A. (2018). Potential reproduction and renewal in a weekend mosque school in Canada: Educators' perspectives of learning and development. Learning, Culture and Social Interaction, 19, 29-39.

Altinyelken, H. K. (2011). Student-centred pedagogy in Turkey: Conceptualisations, interpretations and practices. Journal of Education Policy, 26(2), 137-160.

Altinyelken, H. K. (2015). Evolution of curriculum systems to improve learning outcomes and reduce disparities in school achievement. (EFA GMR background report; No. ED/EFA/MRT/2015/ PI/13). UNESCO. http://unesdoc.unesco.org/images/0023/002324/232420e.pdf.

Altinyelken, H.K., \& Sözeri, S. (2019). Importing mosque pedagogy from Turkey: An analysis of contextual factors shaping re-contextualisation process in the Netherlands. Comparative Education, 55(1), 47-65.

Berglund, J., \& Gent, B. (2019). Qur'anic education and non-confessional religious education: An intercultural perspective. Intercultural Education, 30(3), 323-334.

Bouma, G. (2017). Australia's changing religious profile-rising Nones and Pentecostals, declining British Protestants in superdiversity: Views from the 2016 census. Journal for the Academic Study of Religion, 30(2), 129-143.

Boyle, H. (2006). Memorization and learning in Islamic schools. Comparative Education Review, 50(3), 478-495.

Che Noh, M. A., Tamuri, A. H., Razak, K. A., \& Suhid, A. (2014). The study of Qur'anic teaching and learning: United Kingdom experience. Mediterranean Journal of Social Sciences, 5(16), 313-317.

Cherribi, S. (2010). In the house of war: Dutch Islam observed. Oxford University Press.

Cherti, M., \& Bradley, L. (2011). Inside Madrassas: Understanding and engaging with British-Muslim faith supplementary schools. Institute for Public Policy Research.

Chisholm, L., \& Leyendecker, R. (2008). Curriculum reform in the post-1990s sub-Saharan Africa. International Journal of Educational Development, 28(2), 195-205.

Ennis, C. (1991). Discrete thinking skills in two teachers' physical education classes. The Elementary School Journal, 91, 473-486.

Freire, P. (2009). Pedagogy of the oppressed. The Continuum International.

Giroux, H. A. (1988). Teachers as intellectuals: Toward a critical pedagogy of learning. Bergin \& Garvey.

Grundel, M., \& Maliepaard, M. (2012). Knowing, understanding and practising democratic citizenship: An investigation of the role of religion among Muslim, Christian and non-religious adolescents. Ethnic and Racial Studies, 35(12), 2075-2096.

Hand, M. (2002). Religious upbringing reconsidered. Journal of Philosophy of Education, 36(4), $545-557$.

Hanushek, E. A., \& Wößmann, L. (2008). The role of cognitive skills in economic development. Journal of Economic Literature, 46(3), 607-668.

Hardaker, G., \& Sabki, A. A. (2015). Islamic pedagogy and embodiment: An anthropological study of a British Madrasah. International Journal of Qualitative Studies in Education, 28(8), 873-886. 
Hella, E., \& Wright, A. (2009). Learning 'about' and 'from' religion: Phenomenography, the variation theory of learning and religious education in Finland and the UK. British Journal of Religious Education, 31(1), 53-64.

Huijnk, W. (2018). De religieuze beleving van moslims in Nederland: diversiteit en verandering in beeld [The religious practices of Muslims in the Netherlands: An overview of diversity and change]. Den Haag: Sociaal en Cultureel Planbureau.

Jackson, R. (2014). 'Signposts': Policy and practice for teaching about religions and non-religious worldviews in intercultural education. Council of Europe Publishing.

Jawoniyi, O. (2015). Religious education, critical thinking, rational autonomy, and the child's right to an open future. Religion and Education, 39(1), 34-53.

Jones, P., \& Haydon, D. (2012). Learning to think critically. In P. Jones \& D. Haydon (Eds.), Putting it into practice: Developing student critical thinking skills in teacher education-the models, methods, experiences and results (pp. 1-12). Charlotte: Information Age Pub.

Kalin, I. (2011). Islamophobia and the limits of multiculturalism. In J. L. Esposito \& I. Kalin (Eds.), Islamophobia: The challenge of pluralism in the 21st century (pp. 3-20). Oxford University Press.

Lai, E. R. (2011). Critical thinking: A literature review. Retrieved from http://www.pearsonassessme nts.com/hai/images/tmrs/CriticalThinking. Accessed 5 Feb 2020.

Lipiäinen, T., Ubani, M., Viinikka, K., \& Kallioniemi, A. (2020). What does "new learning" require from religious education teachers? A study of Finnish RE teachers' perceptions. Journal of Religious Education, 68, 213-231.

LMTF (Learning Metrics Task Force). (2013). Toward universal learning: What every child should learn (Report No. 1 of the Learning Metrics Task Force). UNESCO Institute for Statistics and Brookings Institute.

Moore, L. C. (2012). Muslim children's other school. Childhood Education, 88(5), 298-303.

Neubauer, B. E., Witkop, C. T., \& Varpio, L. (2019). How phenomenology can help us learn from the experiences of others. Perspectives on Medical Education, 8, 90-97.

Niyozov, S. (2016). Religious pluralism and Islamic education: Addressing mutual challenges. In N. A. Memon \& M. Zaman (Eds.), Philosophies of Islamic education: Historical perspectives and emerging discourses (pp. 202-219). Routledge.

Nosich, G. (2009). Learning to think things through: A guide to critical thinking across the curriculum. Upper Saddle River: Pearson Education.

Patton, M. Q. (2002). Qualitative research and evaluation methods. Sage Publications.

Pels, T. (2014). Dilemmas of educating Muslim children in the Dutch immigration context. In M. Sedgwick (Ed.), Making European Muslims. Religious socialization among young Muslims in Scandinavia and Western Europe (pp. 56-73). Routledge.

Pels, T., Lahri, F., \& El Madkouri, H. (2006). Pedagogiek in de Moskee Othman [The pedagogy in the Othman Mosque]. Verwey-Jonker Instituut and FORUM.

Perry, D. (2004). Muslim child disciples, global civil society, and children's rights in Senegal: The discourses of strategic structuralism. Anthropological Quarterly, 77(1), 47-86.

Phalet, K., Fleischmann, F., \& Stoijcic, S. (2012). Ways of 'being Muslim': Religious identities of second-generation Turks. In M. R. J. Crul, J. Schneider, \& F. Lelie (Eds.), The European second generation compared: Does the integration context matter? (pp. 341-373). Amsterdam University Press.

Schuitema, J., ten Dam, G., \& Veugelers, W. (2008). Teaching strategies for moral education: A review. Journal of Curriculum Studies, 40(1), 69-89.

Schweisfurth, M. (2013). Learner-centred education in international perspective: Whose pedagogy for whose development? Routledge.

Selim, N. M. (2018). Between the school and the mosque: Young Dutch Moroccan and Dutch Egyptian Muslims negotiating citizenship in the Netherlands (Unpublished MA thesis). University of Amsterdam.

Sieckelinck, S., Essousi, A., \& El Madkouri, H. (2012). Improving after-school education in Dutch mosques: a matter of control or empowerment? In K. Hicham \& B. Abdelhamid (Eds.), Social work, human development and empowerment of skills: A cross-cultural approach (pp. 143-159). APN e-book. Retrieved from: http://arabpsynet.com/apneBooks/eB25HS-3SpringInstitute.pdf. Accessed 8 Jan 2020.

Soyer, E. (2020). Between the school and the mosque: How do Turkish Dutch Muslim adolescents find their way in the Netherlands? Unpublished Master Thesis. University of Amsterdam. 
Sözeri, S. (2021). The pedagogy of the mosque: Portrayal, practice, and role in the integration of Turkish-Dutch children. Gildeprint.

Sözeri, S., \& Altinyelken, H.K. (2019). What are children being taught in the mosque? Turkish mosque education in the Netherlands. Learning, Culture and Social Interaction, 22, [100326].

Sözeri, S., Altinyelken, H.K., \& Volman, M. (2019). Training imams in the Netherlands: The failure of a post-secular endeavour. British Journal of Religious Education, 41(4), 435-445.

Sözeri, S., Altinyelken, H.K., \& Volman, M. (2021). Pedagogies of Turkish mosque education in the Netherlands: An ethno-case study of mosque classes at Milli Görüş and Diyanet. Journal of Muslims in Europe, 10(2), 210-233.

Statistics Nederland. (2019). Bevolking; leeftijd, migratieachtergrond, geslacht en regio, 1 januari [Population; age, migration background, gender and region, 1 January]. The Hague: CBS. Retrieved from: https://opendata.cbs.nl/statline/\#/CBS/nl/dataset/37713/table?ts=1569010613 835. Accessed 8 Jan 2020.

ten Dam, G., \& Volman, M. (2004). Critical thinking as a citizenship competence: Teaching strategies. Learning and Instruction, 14(4), 359-379.

Ucan, A. D., \& Wright, A. (2019). Improving the pedagogy of Islamic religious education through an application of critical religious education, variation theory and the learning study model. British Journal of Religious Education, 41(2), 202-217.

Van Meeteren, M., Van de Pol, S., Dekker, R., Engbersen, G., \& Snel, E. (2013). Destination Netherlands. History of immigration and immigration policy in the Netherlands. In J. Ho (Ed.), Immigrants (pp. 113-170). Nova Science Publishers.

Veugelers, W. (2007). Creating critical-democratic citizenship education: Empowering humanity and democracy in Dutch education. Compare, 37(1), 105-119.

Waghid, Y. (2014). Islamic education and cosmopolitanism: A philosophical interlude. Studies in Philosophy and Education, 33, 329-342.

Westheimer, J. (2008). On the relationship between political and moral engagement. In F. Oser \& W. Veugeler (Eds.), Getting involved. Global citizenship development and sources of moral values (pp. 17-29). Sense Publishers.

Willingham, D. T. (2008). Critical thinking: Why is it so hard to teach? Arts Education Policy Review, 109(4), 21-29.

Witteman, J. (2009). Erbarmelijke Omstandigheden op Koranscholen [Appalling conditions in Qur'an schools]. University of Amsterdam.

Publisher's Note Springer Nature remains neutral with regard to jurisdictional claims in published maps and institutional affiliations. 